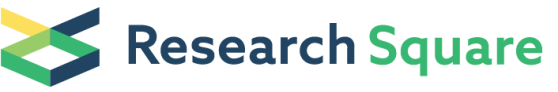 \\ Preprints are preliminary reports that have not undergone peer review. \\ They should not be considered conclusive, used to inform clinical practice, or referenced by the media as validated information.
}

\section{Paramyotonia congenita with persistent distal and facial muscle weakness: A case report with literature review}

\author{
Madoka Mori-Yoshimura ( $\nabla$ yoshimur@ncnp.go.jp) \\ National Center Hospital, National Center of Neurology and Psychiatry \\ Tomoya Taminato
}

Department of Neurology, National Center Hospital, National Center of Neurology and Psychiatry Jun Miki

Department of Neurology, Saku Central Hospital, Nagano Prefectural Federation of Agricultural Cooperative for Health and Welfare

\section{Ryogen Sasaki}

Department of Neurology, Mie National Hospital

\section{Noriko Satoh}

Department of Radiology, National Center Hospital, National Center of Neurology and Psychiatry

\section{Yasushi Oya}

Department of Neurology, National Center of Neurology and Psychiatry

\section{Ichizo Nishino}

Department of Neuromuscular Research, National Institute of Neuroscience, National Center of Neurology and Psychiatry

\section{Yuji Takahashi}

Department of Neurology, National Center of Neurology and Psychiatry

\section{Case report}

Keywords: Paramyotonia congenita, persistent distal hand weakness, temporal muscle, strabismus, SCN4A, T1313M, short exercise test, acetazolamide chloride

Posted Date: February 20th, 2019

DOI: https://doi.org/10.21203/rs.2.359/v1

License: (c) (i) This work is licensed under a Creative Commons Attribution 4.0 International License. Read Full License 
Version of Record: A version of this preprint was published at Journal of Neuromuscular Diseases on March 20th, 2020. See the published version at https://doi.org/10.3233/JND-190440. 


\section{Abstract}

Introduction: Paramyotonia congenita (PC; OMIM 168300) is a non-dystrophic myotonia caused by mutations in the SCN4A gene. Transient muscle stiffness, usually induced by exposure to cold and aggravated by exercise, is the predominant clinical symptom, and interictal persistent weakness is uncommon.

Case presentation: We report a family with a history of PC accompanied by persistent distal hand dominant muscle weakness with masticatory muscle involvement. Persistent weakness was exacerbated with age, and MR analysis showed marked atrophy of temporal, masseter, and finger flexor muscles with fatty replacement. Cases within the family harbor the prevalent PC causative mutation, T1313M, in the SCN4A gene. Administration of acetazolamide chloride improved clinical symptoms and the results of cold and short exercise tests. Phenotypic variation within the family was remarkable, as the two younger affected patients did not present with persistent weakness or muscle atrophy.

Conclusions: PC associated with the T1313M mutation is a possible cause of persistent distal hand weakness.

\section{Background}

Paramyotonia congenita (PC, OMIM 168300) is a non-dystrophic myopathy caused by mutations in the sodium channel protein type 4 subunit alpha (hNaV1.4), which is encoded by the SCN4A gene [1]. PC symptoms are diverse and can overlap with those of hNaV1.4 channelopathies, but a hallmark of the PC phenotype is the marked exacerbation of muscle rigidity upon exposure to cold (paramyotonia). Clinical symptoms of PC are thought to be present at birth and often remain unchanged for life, and muscle atrophy or hypertrophy is not typical for the disease [2].

Persistent muscle weakness in PC patients is rare [2], but a small number of case reports have reported patients who presented with mild weakness (mainly proximal dominant) [3-12]. Here, we present the detailed phenotype of a Japanese PC family presenting with severe distal weakness together with masticatory muscle involvement. Muscle MRI revealed marked fatty infiltration and atrophy of temporal, masseter, and finger muscles. In addition, we review previous reports of PC patients to investigate the nature and frequency of weakness among this population. This is the first report, to our knowledge, that provides detailed muscle images of PC patients that reveal the myopathic nature of the weakness. Furthermore, we performed a literature review on previously reported cases of paramyotonia congenita, including only those in which genetic analysis was performed and clinical information was provided. Written consent for publication was obtained from all patients.

\section{Case Presentation}

\section{Case 1 (III-2)}


The proband had no developmental abnormalities. Since childhood, she had difficulty gripping horizontal bars, and had trouble writing during the winter and on days with cold weather (or with a sudden drop of temperature), which she had no problems with during the summer and on days with warm weather. During elementary school, she noticed a feeling of weakness whenever she suddenly used her muscles, felt stiffness of muscles after running 30-m full power in a 50-m short track sprint, and was unable to keep running after a 50-m sprint. She also had difficulty chewing and became aware of fatigue upon chewing firm food. In her 40 s, she had difficulties opening pull-tabs, even on days with hot weather. She had noticed that her grip power was weaker than others. When finger weakness worsened, she visited our hospital at age 61. She recalled that her mother (case II-2) experienced similar finger weakness and muscle stiffness.

On examination, she presented with right strabismus, and her extraocular movements were limited except for left extension. She had paramyotonia of the eyelids and masseter muscle. Her temporal and masseter muscles were atrophic and a narrow high-arched palate was observed. The manual muscle test revealed distal dominant weakness (Table 1). Grip power was $1 / 1 \mathrm{~kg}$, forearm and intrinsic muscles were atrophic, and the proximal interphalangeal joint was hyperextended. Although she had mild weakness of proximal muscles, her shoulder muscles or lower limb muscles were mildly hypertrophic. Deep tendon reflexes were normal, and there were no other abnormalities. CK was $127 \mathrm{IU} / \mathrm{L}$ (within normal range). Needle electromyogram revealed myopathic changes together with abundant myotonic discharges in all muscles examined. A short exercise test stimulating the ulnar nerve showed marked decrement of compound muscle action potential (CMAP) after exercise to $20 \%(1.10 \mathrm{mV})$ of the baseline value $(5.59 \mathrm{mV})$, with subsequent partial recovery (Figure $2 \mathrm{~A}$ ). The cooling test also revealed marked decrement of CMAP to $4 \%$ $(0.36 \mathrm{mV})$ of the baseline value $(8.96 \mathrm{mV})$ (Figure $2 \mathrm{~B})$. Muscle CT revealed mild hypertrophy of proximal muscles, and low density and atrophy of the forearms (Figure 3). Forearm MRI revealed fatty changes and atrophy of forearm muscles, especially the flexor digitorum profundus, flexor digitorum superficialis, extensor pollicis index and longus, supinator, and adductor pollicis longus muscles, whereas flexor carpi radialis and flexor carpi ulnaris muscles were relatively spared (Figure 4A-E). Cranial MRI revealed temporal and masseter muscle atrophy with fatty replacement (Figure 4F-H). There were no abnormal findings on ECG, UCG, holter ECG, pulmonary function tests, nocturnal respiratory monitoring, and videofluorography. No abnormalities were found in the DMPK and $C N B P$ genes. However, analysis of the SCN4A gene revealed a C to T mutation at c. 3938 in exon 22 (p.T1313M). We also examined genomic DNA isolated from peripheral blood by whole-exome sequencing using Hiseq1000 (Illumina) and sequence data analyses, as described previously [13], but no additional abnormalities were found.

Administration of acetazolamide 500mg improved her paramyotonia except for persistent weakness. The time needed for 10 serial handgrips and 10 serial squats improved from 29.1 seconds to 13.9 seconds and 29.3 seconds to 17.2 seconds, respectively. Serial grip power measurements also improved from $15 \%$ ( $2 \mathrm{~kg}$ to $0.3 \mathrm{~kg}$ ) to $88 \%$ (2.5 kg to $2.2 \mathrm{~kg}$ ). In short exercise and cooling tests, CMAP increased relative to before drug administration, and CMAP decrement after exercise also improved with drug administration (Figures 2A and 2B). 


\section{Case 2(III-1)}

The patient had poor physical performance in her school days, and she was aware of hand weakness. She could not grip horizontal bars or a tennis racket to the end of a game. She felt tired when chewing tough meat. These symptoms worsened in the winter. She visited a neurologist in her late 40 s and was diagnosed with myopathy following $\mathrm{nEGM}$ examination. The administration of mexiletine hydrochloride $150 \mathrm{mg}$ was started; however, her symptoms did not improve. When she visited the neurologist again at age 63 , she presented with facial muscle involvement and temporal muscle atrophy, as well as distal arm muscle atrophy, weakness, and grip myotonia that worsened with recurrent grips. She had no difficulty walking. Deep tendon reflexes were reduced in the arms, but no other abnormalities were observed. EMG revealed abundant myotonic discharges. Her daughter (IV-2) had similar symptoms.

\section{Case 3 (IV-6)}

The patient had difficulty fastening buttons and writing during the winter since childhood. She also noticed that repeated handgrips resulted in weakness. She was a slow runner and had poor physical performance in her school days. She felt her legs became very "stiff" like clubs, and could not run in cold temperature conditions. She visited a neurologist at age 24 . On examination, she presented with grip and eyelid paramyotonia. No weakness or muscle atrophy was noted. Deep tendon reflexes were normal. Administration of acetazolamide chloride $250 \mathrm{mg}$ did not improve her quality of life. Her brother (IV-5) had similar symptoms.

\section{Discussion And Conclusions}

This is the first report of significant distal and cranial persistent muscle weakness and atrophy identified by muscle imaging in PC patients. Most reports on persistent weakness focused on proximal weakness, whereas our cases and another Japanese study [7] reported distal weakness among patients harboring a T1313M mutation in the SCN4A gene. Among the three affected members, two had mild grip weakness [7].

We reviewed case reports that mentioned neurological examinations of patients who have mutations in the SCN4A gene, and identified reports describing those positive for persistent or fixed weakness in the interictal phase. Patients described as having "no persistent/fixed weakness" or "no weakness, or no abnormal findings in neurological examination" were considered "no persistent weakness" cases. In the 44 papers analyzed (more than 76 pedigrees, 236 cases, Table 2), 42 patients (18\%) had persistent weakness [3-15], 124 (53\%) had no persistent weakness, and 70 (30\%) had no description about weakness. Among those with persistent weakness, 4/42 (10\%) were aged under 30 years, whereas 17/43 (40\%) were 30 years and above, and age was unknown in 21/42 (50\%). Of the 42 patients with persistent weakness, 16 had proximal weakness [3-5,10-12], five had mild distal hand weakness [6, 10], and there was no description regarding weakness distribution for 26 patients [7, 9]. Among 29 patients carrying the SCN4A T1313M mutation, 3/29 had persistent weakness [6, 10], 16/29 had no weakness, and no description was provided for 10/29. 
The marked persistent weakness, muscle atrophy, and fatty changes observed in our cases reveal the myopathic nature of the disease. As Bednardz suggested [12], the pathogenesis of sodium-channel myopathies may involve increased sodium influx and osmotic edema that strangulate T-tubules, leading to fiber necrosis and stimulation of new T-tubule proliferation, vacuolar formation [14, 15], and hyperosmotic stress with mitochondrial degeneration [16]. Persistent weakness was more prevalent among patients aged over 30 years than those under 30 years (Tables 2 and 3 ). Recurrent myofiber stress may responsible for fiber damage due to necrosis.

In this study, we were able to detect both muscle atrophy and fatty replacement by MRI and CT imaging. An ultrasound study of 19 sodium channelopathy cases, including 10 PC cases, revealed increased echointensity in the biceps brachii and forearm flexors [17]. Our study provides further detail by showing that flexor digitorum superficialis and flexor digitorum profundus muscles were strongly involved among forearm flexors. These findings are compatible with the observations of marked finger weakness, facial muscle atrophy, and fatty changes. Moreover, muscles with severe transient weakness, such as finger, facial, and masseter muscles, were markedly myopathic among muscles.

Case III-2 presents a remarkable case in that it is the first PC patient who presented with strabismus and an arched palate. A few reports have been published regarding strabismus among SCN4A-related myotonia cases, but none of the cases were PC patients $[9,18]$. Strabismus and/or diplopia was reported in $47 \%$ of children with SCN4A-related myotonia among those with sodium channelopathies [9], indicating an overlap in phenotype. Previous reports on facial involvement and arched palate involved a myopathy patient with a recessive loss-of-function mutation who did not present with myotonic features among those carrying SCN4A mutations $[19,20]$. Severe facial muscle involvement may potentially explain the arched palate.

The paramyotonia observed in our patients improved with acetazolamide chloride and, similar to previous reports [21-23], we clearly described the electrophysiological interval changes. As the pathogenesis of muscle damage resulted from functional abnormalities in NaV1.4, improvement of these abnormalities may help counter persistent weakness.

In conclusion, PC patients harboring SCN4A mutations can present with persistent weakness of distal hand and cranial muscles. Phenotype varies even within a family and with age. Therapeutic approaches may counter the progression of persistent weakness.

\section{Abbreviations}

PC: Paramyotonia congenita

hNaV1.4: sodium channel protein type 4 subunit alpha

CMAP: compound motor action potential

ECG: electrocardiogram 
UCG: echocardiogram

\section{Declarations}

\section{Ethics approval and consent to participate}

This study was approved by the Ethics Committee of the National Center of Neurology and Psychiatry (NCNP). Written informed consent was signed by each participant.

\section{Consent for publication}

Not applicable.

\section{Availability of data and materials}

The datasets used and/or analyzed during the current study (e.g., the details of mutational data) are available from the corresponding author on reasonable request.

\section{Competing interests}

The authors declare that they have no competing interests.

\section{Funding}

This study was supported partly by an Intramural Research Grant (23-4, 26-7, 28-6, and 29-4) for Neurological and Psychiatric Disorders of NCNP, Research and Development Grants for Practical Research Project for Rare/Intractable Diseases (16ek0109066h0003), and Research Grants for Nervous and Mental Disorders (20-11) from the Ministry of Health, Labour and Welfare of Japan. The role of the funding body was restricted to finance the first author for data collection, draft and revision of the article

\section{Author contributions}

TT collected the data and drafted/revised the manuscript. MMY developed the study concept/design, acquired the data, analyzed and interpreted the data, supervised the study, and drafted/revised the manuscript. JM collected the patient data. NS collected the radiological data and revised the manuscript. RS collected the patient data and interpretation, and revised the manuscript. YO collected the patient data. IN performed genetic analysis and revised the manuscript. YT revised the manuscript critically for intellectual content.

\section{Acknowledgement}

Not applecable.

\section{References}


1. Lehmann-Horn F, Rudel R, and Jurkat-Rott K. Nondystrophic myotonias and periodic paralyses. In: Engel AG, Fanzini-Armstrong C, editors. Myology, Basic and Clinical, 3rd Edition. NewYork: McGrawHill; 2004. p 1267-1289.

2. Ptacek LJ, Trimmer JS, Agnew WS, Roberts JW, Petajan JH, Leppert M. Paramyotonia congenita and hyperkalemic periodic paralysis map to the same sodium-channel gene locus. Am J Hum Genet. 1991;49:851-854.

3. Kelly P, Yang WS, Costigan D, Farrell MA, Murphy S, Hardiman O. Paramyotonia congenita and hyperkalemic periodic paralysis associated with a Met 1592 Val substitution in the skeletal muscle sodium channel alpha subunit-a large kindred with a novel phenotype. Neuromuscul Disord. 1997;7:105-111.

4. Kim J, Hahn Y, Sohn EH, Lee YJ, Yun JH, Kim JM, et al. Phenotypic variation of a Thr704Met mutation in skeletal sodium channel gene in a family with paralysis periodica paramyotonica. $\mathrm{J}$ Neurol Neurosurg Psychiatry. 2001;70:618-623.

5. Brancati F, Valente EM, Davies NP, Sarkozy A, Sweeney MG, LoMonaco M, et al. Severe infantile hyperkalaemic periodic paralysis and paramyotonia congenita: broadening the clinical spectrum associated with the T704M mutation in SCN4A. J Neurol Neurosurg Psychiatry. 2003;74:1339-1341.

6. Kinoshita M, Sasaki R, Nagano T, Matsuda A, Nakamura S, Takahama M, et al. Thr1313Met mutation in skeletal muscle sodium channels in a Japanese family with paramyotonia congenita. Intern Med. 2003;42:856-61.

7. Miller TM, Dias da Silva MR, Miller HA, Kwiecinski H, Mendell JR, et al. Correlating phenotype and genotype in the periodic paralyses. Neurology. 2004 9;63:1647-55.

8. Schoser BG, Schröder JM, Grimm T, Sternberg D, Kress W. A large German kindred with coldaggravated myotonia and a heterozygous A1481D mutation in the SCN4A gene. Muscle Nerve 2007;35:599-606.

9. Matthews E, Fialho D, Tan SV, Venance SL, Cannon SC, Sternberg D, et al. The non-dystrophic myotonias: molecular pathogenesis, diagnosis and treatment. Brain 2010;133:9-22.

10. Khadilkar SV, Singh RK, Mansukhani KA, Urtizberea JA, Sternberg D. Relief from episodic weakness with pyridostigmine in paramyotonia congenita: a family study. Muscle Nerve. 2010;41:133-7.

11. Matthews E, Silwal A, Sud R, Hanna MG, Manzur AY, Muntoni F, et al. Skeletal Muscle Channelopathies: Rare Disorders with Common Pediatric Symptoms. J Pediatr. 2017 ;188:181-5.

12. Bednarz M, Stunnenberg BC, Kusters B, Kamsteeg EJ, Saris CG, Groome J, et al. A novel lle1455Thr variant in the skeletal muscle sodium channel alpha-subunit in a patient with a severe adult-onset proximal myopathy with electrical myotonia and a patient with mild paramyotonia phenotype. Neuromuscul Disord. 2017;27:175-82.

13. Endo Y, Noguchi S, Hara Y, Hayashi YK, Motomura K, Miyatake S, et al. Dominant mutations in ORAl1 cause tubular aggregate myopathy with hypocalcemia via constitutive activation of store-operated $\mathrm{Ca}^{2} \rrbracket$ channels. Hum Mol Genet. 2015;24:637-48. doi: 10.1093/hmg/ddu477. 
14. Basali D, Prayson RA. Episodic weakness and vacuolar myopathy in hypokalemic periodic paralysis. J Clin Neurosci 2015;22:1846-7.

15. Engel AG, Franzini-Armsrong C. Myology. In: Engel AG, Franzini-Armstrong C, editors. Myology: basic and clinical, vol. 2. 3rd ed. New York: McGraw-Hill; 2004. p. 1282-1287.

16. Haldar D, Freeman KB. Importance of the osmolarity of the incubation medium on amino acid incorporation into protein by isolated rat liver mitochondria. Biochem J 1969;111:653-61.

17. Trip J, Pillen S, Faber CG, van Engelen BG, Zwarts MJ, Drost G. Muscle ultrasound measurements and functional muscle parameters in non-dystrophic myotonias suggest structural muscle changes. Neuromuscul Disord. 2009;19:462-7.

18. Du H, Grob SR, Zhao L, Lee J, El-Sahn M, Hughes G, et al. Myotonia congenita with strabismus in a large family with a mutation in the SCN4A gene other than PC. Eye (Lond). 2012;26:1039-1043. doi: 10.1038/eye.2012.80. Epub 2012 Jun 1.

19. Gonorazky HD, Marshall CR, Al-Murshed M, Hazrati LN, Thor MG, Hanna MG, et al. Congenital myopathy with "corona" fibres, selective muscle atrophy, and craniosynostosis associated with novel recessive mutations in SCN4A. Neuromuscul Disord. 2017;27:574-80

20. Zaharieva IT, Thor MG, Oates EC, van Karnebeek C, Hendson G, Blom E, et al. Loss-of-function mutations in SCN4A cause severe foetal hypokinesia or 'classical' congenital myopathy. Brain. 2016;139(Pt 3):674-91

21. Alfonsi E, Merlo IM, Tonini M, Ravaglia S, Brugnoni R, Gozzini A, et al. Efficacy of propafenone in paramyotonia congenita.Neurology. 2007;68:1080-1.

22. Jackson CE, Barohn RJ, Ptacek LJ. Paramyotonia congenita: abnormal short exercise test, and improvement after mexiletine therapy.

23. Feng Y, Zhang Y, Liu ZL, Zhang CD. Exercise test on the patients with normokalaemic periodic paralysis from a Chinese family with a mutation in the SCN4A gene. Chin Med J (Engl). 2008 5;121(19):1915-9.

\section{Tables}




\begin{tabular}{|c|c|c|c|c|c|}
\hline \multicolumn{3}{|l|}{ Case } & 1 & 2 & 5 \\
\hline \multicolumn{3}{|l|}{ Pedigree ID } & III-2 & IIII-1 & IV-6 \\
\hline \multicolumn{3}{|c|}{ Age (years), sex } & $61, F$ & $62, \mathrm{~F}$ & $24, \mathrm{M}$ \\
\hline \multicolumn{3}{|c|}{ age at onset } & around 10 & around 10 & childhood \\
\hline \multicolumn{3}{|l|}{ Strabismus } & + & - & - \\
\hline \multicolumn{3}{|c|}{ high-arched palate } & + & & - \\
\hline \multicolumn{3}{|c|}{ Extraocular paralysis } & + & - & - \\
\hline \multicolumn{3}{|c|}{ Facial involvement } & + & + & - \\
\hline \multirow[t]{3}{*}{ Paramyotonia } & \multicolumn{2}{|l|}{ eyelid } & + & + & + \\
\hline & \multicolumn{2}{|l|}{ hand grip } & + & + & - \\
\hline & \multicolumn{2}{|l|}{ leg } & + & + & + \\
\hline \multirow[t]{16}{*}{ MMT } & \multirow[t]{2}{*}{ neck } & flexion & 2 & 4 & 5 \\
\hline & & extension & 2 & NT & 5 \\
\hline & \multirow[t]{2}{*}{ shoulder } & abduction & $3 / 3$ & 4 & 5 \\
\hline & & extension & $2 / 2$ & NT & $5 / 5$ \\
\hline & \multirow[t]{2}{*}{ elbow } & flexion & $4 / 4$ & $3 / 3$ & $5 / 5$ \\
\hline & & extension & 4 & $3 / 3$ & $5 / 5$ \\
\hline & \multirow[t]{2}{*}{ wrist } & flexion & 2 & 2 & $5 / 5$ \\
\hline & & extension & 2 & 2 & $5 / 5$ \\
\hline & \multirow[t]{2}{*}{ finger } & flexion & $3 / 3$ & $3 / 3$ & $5 / 5$ \\
\hline & & extension & $3 / 3$ & 2 & $5 / 5$ \\
\hline & \multirow[t]{2}{*}{ hip } & flexion & $4 / 4$ & $3 / 3$ & $5 / 5$ \\
\hline & & extension & $4 / 4$ & NT & $5 / 5$ \\
\hline & \multirow[t]{2}{*}{ knee } & flexion & $4 / 4$ & $4 / 4$ & $5 / 5$ \\
\hline & & extension & $4 / 4$ & $4 / 4$ & $5 / 5$ \\
\hline & \multirow[t]{2}{*}{ ankle } & flexion & $3 / 3$ & $4 / 4$ & $5 / 5$ \\
\hline & & extension & $3 / 3$ & $4 / 4$ & $5 / 5$ \\
\hline \multicolumn{3}{|l|}{ Grip } & $1 / 1$ & $0 / 0$ & NT \\
\hline \multicolumn{3}{|c|}{$\begin{array}{l}\text { CMAP decrement in short exercise } \\
\text { test }\end{array}$} & + & NT & NT \\
\hline \multicolumn{3}{|c|}{ CMAP decrement in cooling test } & + & NT & NT \\
\hline \multicolumn{3}{|l|}{$\overline{C K}$} & 126 & NT & NT \\
\hline \multicolumn{3}{|c|}{ ECG } & normal & NT & $\mathrm{NT}$ \\
\hline \multicolumn{3}{|c|}{ UCG } & $\begin{array}{l}\text { EF 65\% moderate mitral valve } \\
\text { regurgitation }\end{array}$ & NT & NT \\
\hline \multicolumn{3}{|c|}{$\% \mathrm{FVC}$} & 103 & NT & NT \\
\hline Therapy & acet & azolamide & effective & NA & $\begin{array}{c}\text { not } \\
\text { effective }\end{array}$ \\
\hline & $\operatorname{mex}$ & letine & NA & $\begin{array}{c}\text { Not } \\
\text { effective }\end{array}$ & NA \\
\hline
\end{tabular}

Due to technical limitations, Tables 2 and 3 have been placed in the Supplementary Files section.

\section{Figures}




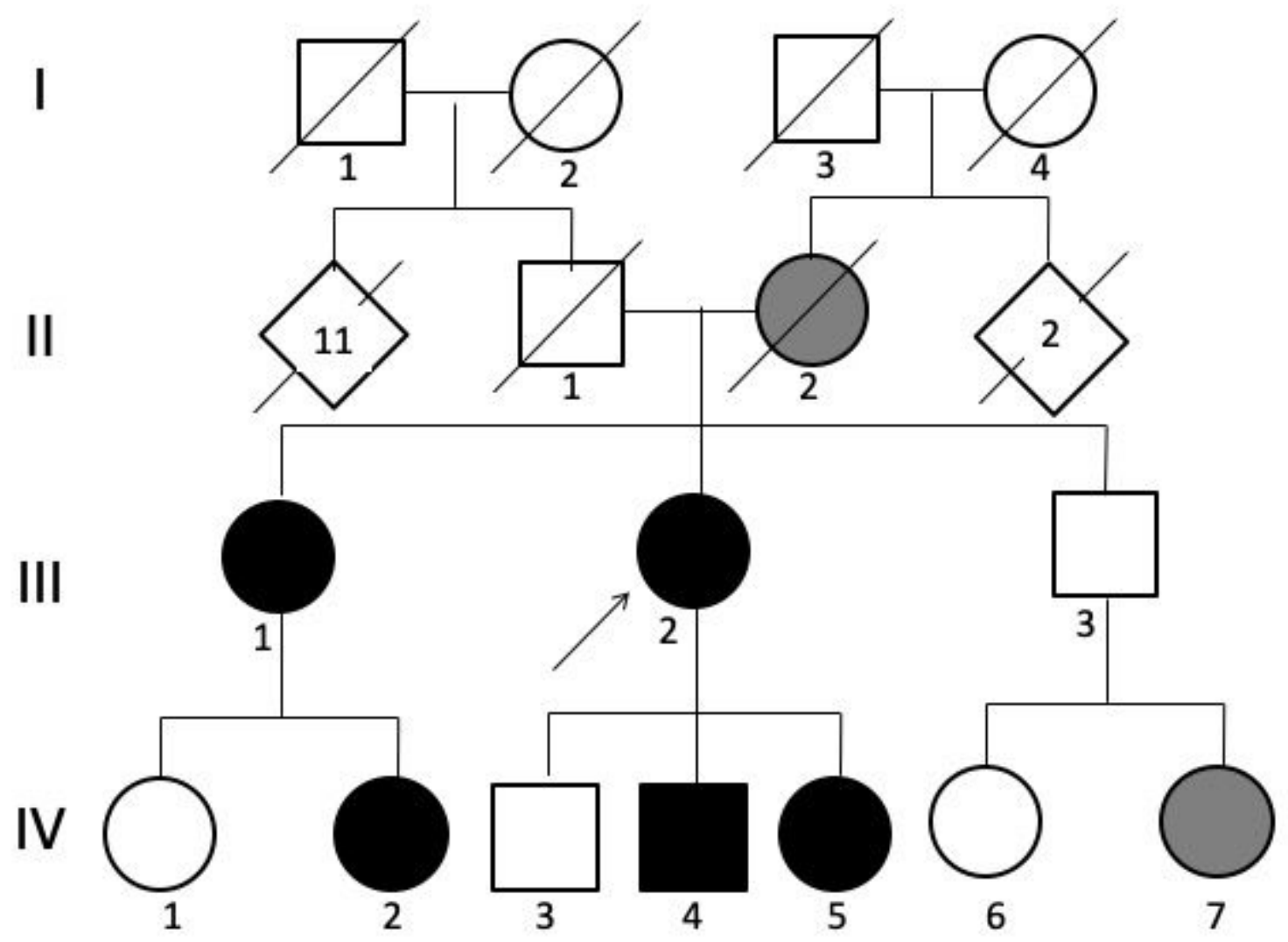

Figure 1

Family tree. Black circle were examined by neurologists and diagnosed with paramyotonia. Cases II-2 and IV-7 (gray) were not diagnosed, but exhibited similar symptoms as cases III-1 and III-2, and thus were suspected of having paramyotonia. 
a.

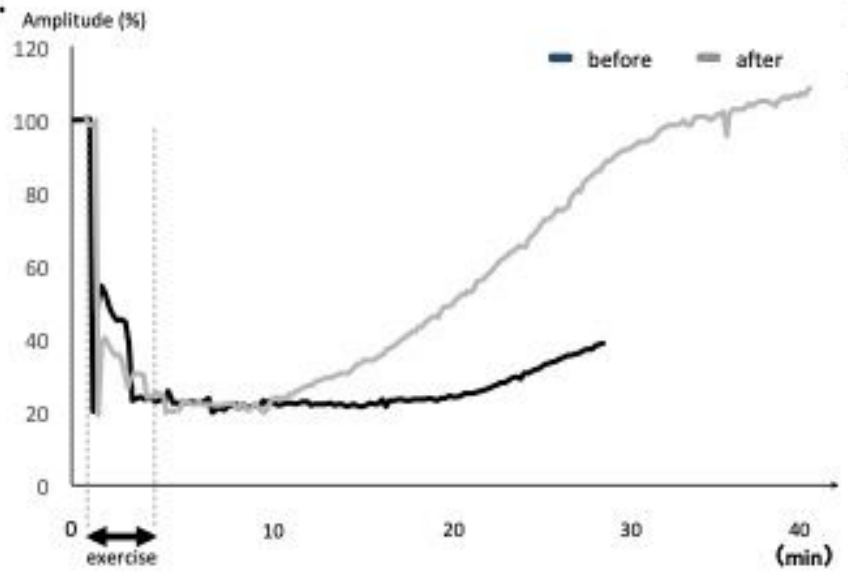

b.

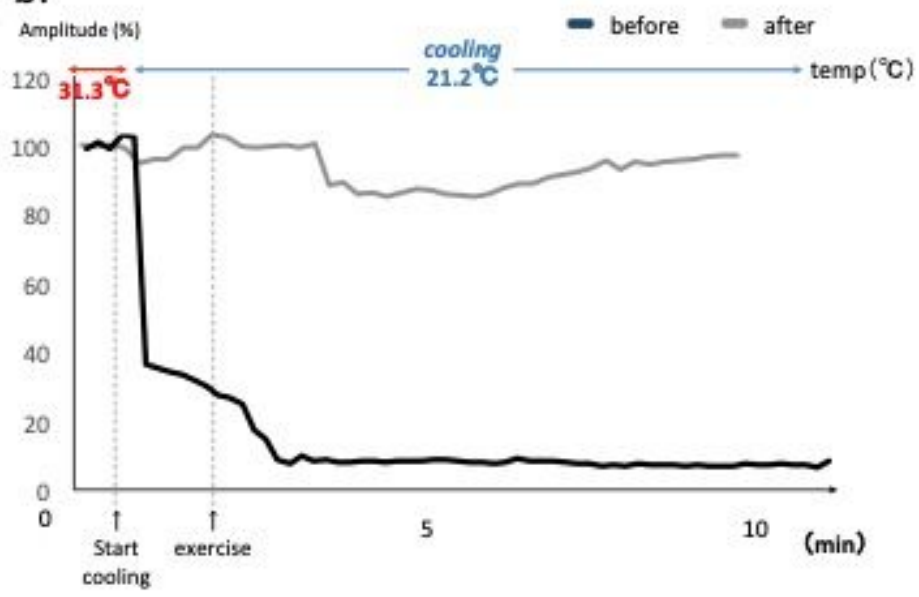

\section{Figure 2}

Electrophysiological Tests on Case III-2. Black line=baseline (before treatment), gray line: after treatment of acetazolamide (A) Short exercise test of right ADM. Marked decrement after exercise to $20 \%(1.10 \mathrm{mV})$ of baseline CMAP (5.59 mV, black line), and partial recovery was observed thereafter (gray line). (B) The cooling test also showed marked decrement to $4 \%(0.36 \mathrm{mV})$ of baseline CMAP (8.96 mV, black line), whereas no significant decrement were observed after treatment (gray line). 

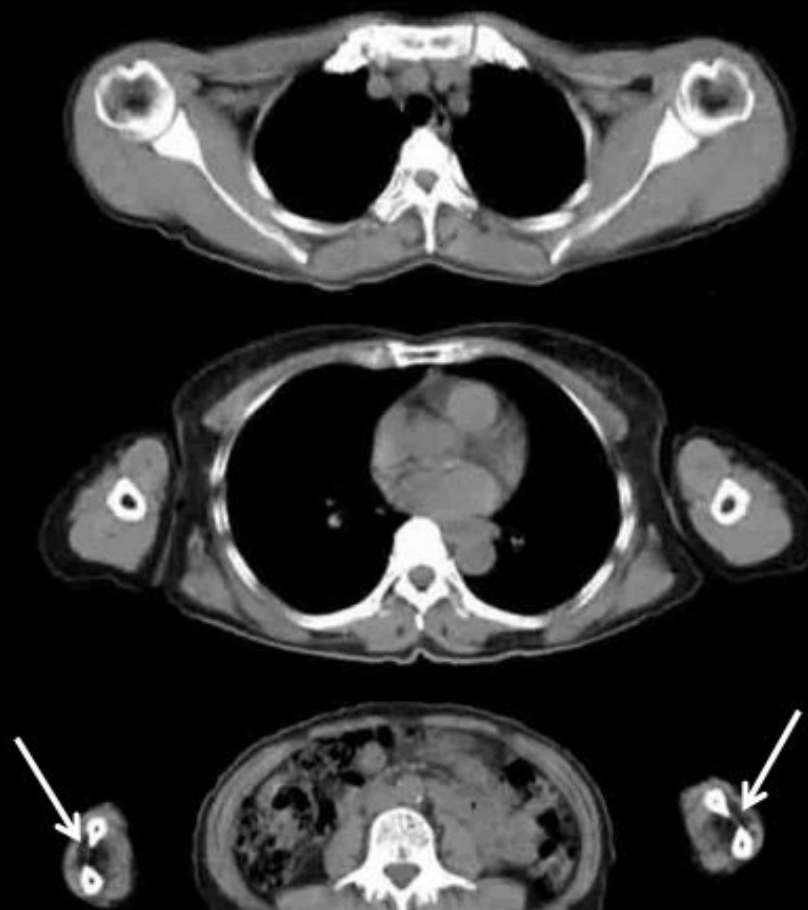

$\mathbf{R}$
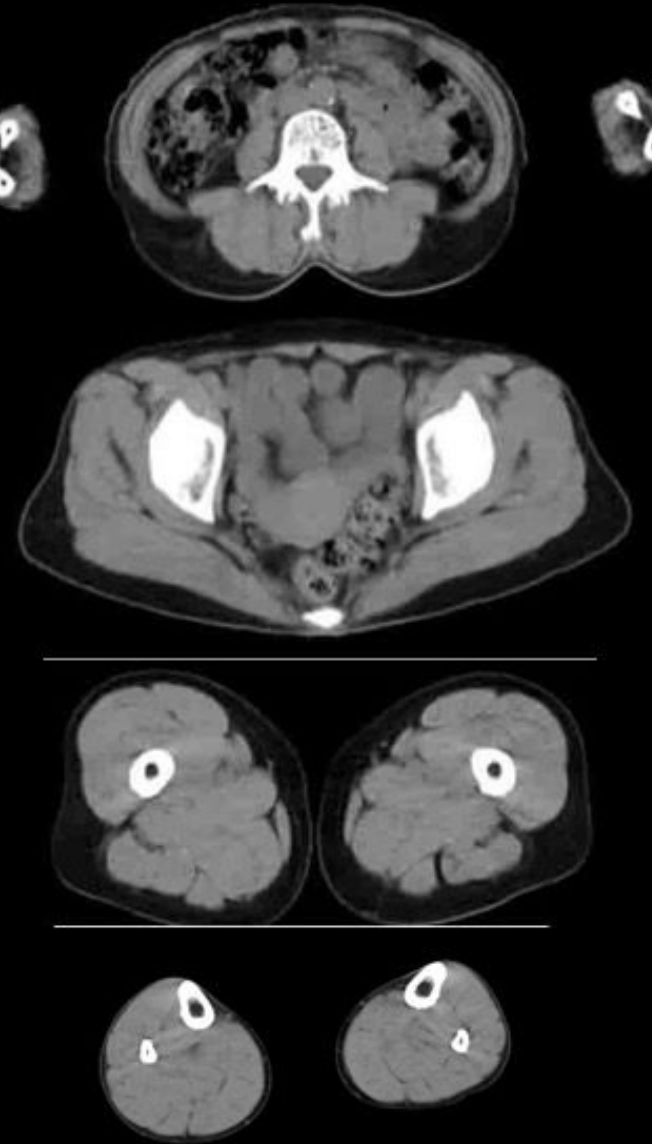

\section{Figure 3}

Muscle CT of Case 2 (III-2). CT showed mild hypertrophy of proximal muscles, with the exception of atrophy and low density of forearm muscles (arrow). 

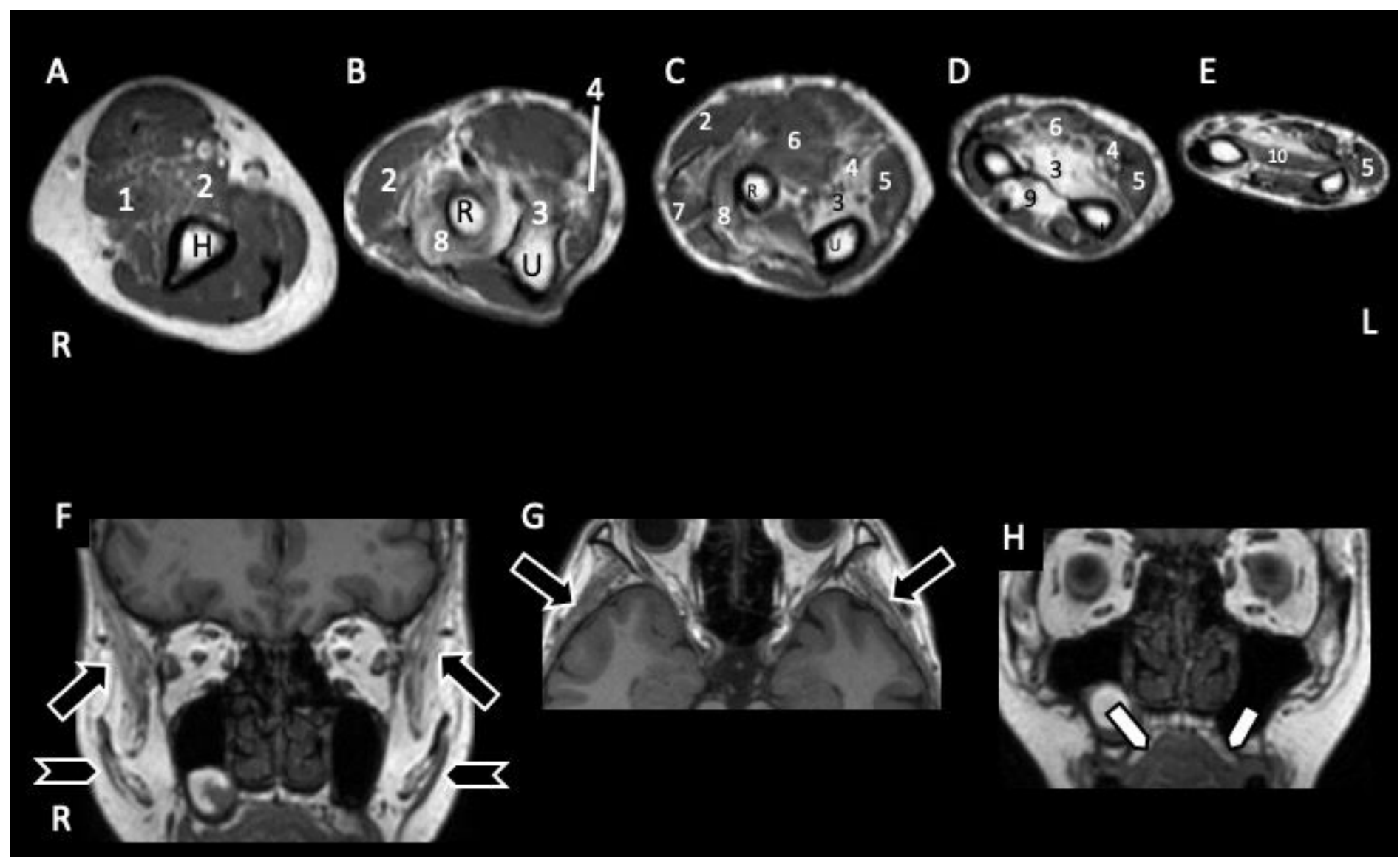

\section{Figure 4}

Muscle and Cranial T1WI MRI of Case 2 (III-2). A; right upper arm, B-E; forearm, F-H; cranial images. U: ulna, R: radius, 1 ; brachialis, 2; brachioradialis, 3 : flexor digitorum profundus (FDP), 4: flexor digitorum superficialis (FDS), 5: flexor carpi ulnaris (FCU), 6: flexor carpi radialis (FCR), 7: extensor carpi radialis (ECR), 8: supinatus, 9: abductor pollicis longus (APL), 10: pronator quadratus (PQ). A: Upper arm muscles were well-preserved, although mild fatty infiltration was observed in brachialis (3) and brachioradialis (2) muscles. B-D: FDP (3), FDS (4), supinatus (8), and ALP (9) showed marked fatty changes and atrophy, whereas FCU (5), FCR (6), and ECR (7) were relatively spared. These findings are compatible with marked finger weakness and loss of grip power. F, G: Temporal muscles (arrows) and masseter muscles (arrow heads) showed marked atrophy and fatty infiltration. H: Arched palate (arrow) was observed.

\section{Supplementary Files}

This is a list of supplementary files associated with this preprint. Click to download.

- supplement1.xlsx 
- supplement2.xlsx

- supplement3.jpg

Page 15/15 